\title{
Public Education Spending and GDP in China: Granger Causality Tests Using Toda-Yamamoto Technique
}

\author{
Gao-lu Zou
}

Faculty of Tourism, Culture and Industrial Development, Chengdu University, Chengdu 610106, Sichuan Province, China

\begin{abstract}
The quantity of national fiscal budget expenditure on education in China has expanded over the past decade. The paper aims to investigate whether GDP may be a significant cause of public education spending. Three series covered the period from 1991-2011. The paper utilized an unconventional Granger causality test in order to deal with the integrated properties of data. Both GDP and CPI Granger caused the share of public education spending to GDP. GDP expansion has contributed significantly to public education spending at least in the short term
\end{abstract}

Index Terms - Fiscal budget expenditure, education, economic growth, Granger causality, Toda-Yamamoto test

\section{Introduction}

China holds the second-largest economy in the world. During the period from 2000-2010, China's gross domestic product (GDP) grew at anannual rate of $15 \%$. Meanwhile, the yearly growth rate of national fiscal budget expenditure on education (FBEE) was 21\% [1]. Hence, the aggregate amount of public education spending (PES) had grown faster than GDP. However, one significant indicatorof public education spending is the percentage of PES to GDP (PES/GDP). The share of PES in GDP was $2.11 \%$ in 1991 , declined slightly to $2.1 \%$ in 2000 and had grown considerably during the period from $2000-2011$. It reached $3.36 \%$ by 2010 . It is noteworthy that the central government was committed to increasing the share of FBEE in GDP to 4\% by 2012 [2].

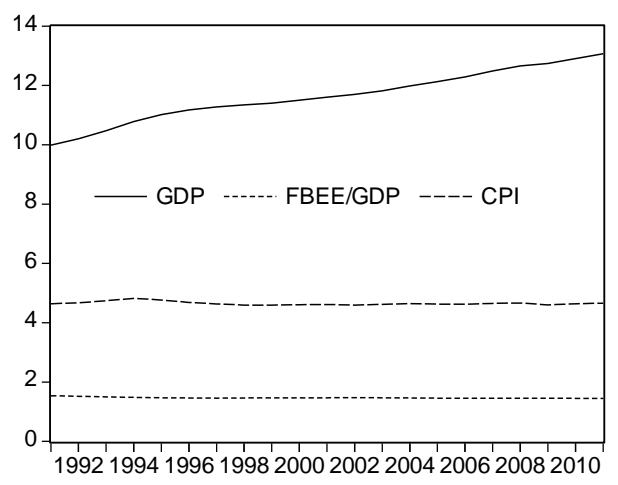

Fig. 1 Logarithmic changes of fiscal budget expenditure on education with GDP and CPI.

Fig. 1 exhibits that the share of FBEE (to GDP) and GDP moved apart. They were negatively correlated (correlation coefficient equaled to -0.83 ). One reason for this may be that high inflation reduced the increase in PESto some extent. Literature argues that fiscal decentralization in China leads to the regional disparities and shrinkage of fiscal spending on education [3-4]. Therefore, we argue that during a relatively long period, fast GDP expansion in China might not lead to PES growth in terms of the share of FBEE to GDP. This paper aims to investigate the causal relation from GDP to the share of PES to GDPin China.

\section{Methods}

If GDP Granger causes PES/GDP, GDP growth may lead to or at least can predict growth in PES/GDP [5]. Conventional Granger causality tests can be conducted within either a vector autogressive (VAR) setting or an errorcorrection model (ECM) [6-7].

However, the conventional Granger causality test requires that time-series variables be integrated of order one. Cointegration is crucial for theconstruction of an ECM. Tests must follow very stringent procedures [8-9]. Time series variablesoften do not consistentlycontaina unit root. In such a case, we could test for Granger causality using the 'unconventional' Toda-Yamamoto test [10]. A bivariate TodaYamamoto test employs a lag-augmented VAR:

$$
y_{t}=\delta_{0}+\delta_{1} t+j_{1} x_{t-1}+\ldots+j_{k} x_{t-k}+j_{k+1} x_{t(k+1)}+\ldots+j_{k+d} x_{t(k+d)}+\varepsilon_{t}
$$

Where $y_{\mathrm{t}}$ and $x_{\mathrm{t}}$ contain at most two orders (denoted $d \leq 2$ ) around a linear trend $(t) . \varepsilon_{\mathrm{t}}$ denotes the error term. The null hypothesis of non-Granger causality from $x$ to $y$ is:

$$
j_{1}=j_{2}=\ldots=j_{k}=0
$$

Wald $\chi^{2}$-statistics for the hypothesis are calculated.

We tested for unit root using the Augmented DickeyFuller (ADF) test [11-12] and the Phillips-Perron (PP) test [13]. We use two unit root tests in order to control for finite sample.

\section{Data}

The study employed yearly time series data. They are nationwide fiscal budget expenditure on education (FBEE), GDP (GDP) and average CPI (CPI) [1]. FBEE represents total public education spending (PES). Data covered the period from 1991-2011. Tests utilized the logarithmic values of data. Table I describes the statistical properties from the data. 
TABLE I Statistical Description for the Original Data

\begin{tabular}{|c|c|c|c|c|c|}
\hline & Mean & Median & Max & Mini & Jarque-Bera $(\mathrm{p}$-value $)$ \\
\hline GDP (RMB100 million) & 11.6 & 11.6 & 13.1 & 10.0 & $0.62(0.73)$ \\
\hline FBEE (RMB10 thousand) & 17.1 & 17.1 & 18.9 & 15.3 & $1.03(0.60)$ \\
\hline FBEE/GDP & 1.47 & 1.46 & 1.54 & 1.45 & $16.6(0.00)$ \\
\hline CPI (preceding year=100) & 4.65 & 4.64 & 4.82 & 4.59 & $10.8(0.00)$ \\
\hline
\end{tabular}

Notes: Data were transformedinto natural logarithms.

\section{Empirical Results}

Table II shows that both ADF and PP tests detected at least two unit roots for the three variables of interest at the 5\% confidence level. Hence, we could not examine causal relations using conventional Granger causality test techniques. Instead, we conducted the Toda-Yamamoto tests (Table III). Table III shows that both GDP and CPI Granger caused FBEE/GDP.

TABLE II Unit Root Tests

\begin{tabular}{|c|c|c|c|c|}
\hline & ADF & PP & Level (lags) & F.D. (lags) \\
\hline & Level (lags) & F.D. (lags) & $-2.49(2)$ & $-1.62(2)$ \\
\hline $\log (\mathrm{GDP})$ & $-2.56(0)$ & $-1.55(0)$ & $-3.11(1)$ & $-2.85(1)$ \\
\hline $\log (\mathrm{FBEE} / \mathrm{GDP})$ & $-3.20(0)$ & $-2.90(0)$ & $-2.12(1)$ & $-2.60(8)$ \\
\hline
\end{tabular}

Notes: F.D. denotes the first difference. Log denotes natural logarithms. Test equations included both the trend and intercept. For ADF regression, lag was selected using modified AIC. For PP regression, lag was chosen utilizing the Newey-West method [14].

TABLE III Toda-Yamamoto Granger Causality Tests

\begin{tabular}{|c|c|c|c|c|c|c|c|}
\hline $\mathrm{H}_{0}$ & Wald- $\chi^{2}$ & $k+d$ & $F$ & Adj. $R^{2}$ & AIC & ARCH & Jarque-Bera \\
\hline GDP does not Grangercause FBEE/GDP & $63.7(0.00)$ & 6 & 544 & 0.99 & -7.27 & $10(0.04)$ & $0.10(0.95)$ \\
\hline CPI does not Grangercause FBEE/GDP & $186(0.00)$ & 6 & 1628 & 0.99 & -8.37 & $9.39(0.05)$ & $0.01(0.99)$ \\
\hline
\end{tabular}

Notes: Data were in natural logarithms.Tests chose the lag length $k$ by reducing AIC to the extent possible. We set $k$ at two to five using general-to-specific techniques [15]. The data contained the maximal order of integration d at two based on the results in Table II. Hence, VAR $(k+2)$ system was estimated.However, we estimated the $\chi^{2}(k)$-statistic to test for $\mathrm{H}_{0}$. ARCH is the LM statistic for no $\mathrm{ARCH}$. The figures in parentheses are p-values.

\section{Concluding Remarks}

With high inflation, the increase in the share of PES to GDP is more meaningful than the increase in total PES. The central government was committed to increasing the proportion of fiscal budget expenditure on education in GDP. If GDP expands quickly and CPI maintains a high level during an extended period, PES may not keep up with GDP while allowing for inflation.

Tests suggested that GDP Granger caused the share of PES to GDP. Hence, in the short term, a significant growth of the share of PES ensues GDP expansion. Fiscal decentralization rarely exertsan adverse effect on public education spending. This finding is inconsistent with several past studies. The contribution of fast GDP expansion to education is significant at least in the short term.

\section{References}

[1] http://data.stats.gov.cn/.

[2] http://news.xinhuanet.com/edu/2010-07/29/c_12389320.htm.

[3] B. Qiao, X. Fan, and J. Feng, "Fiscal decentralization and compulsory primary education in china," Social Sciences In China, vol., no. 6, 37-46, 206, 2005.

[4] L. A. West, and C. P. Wong, "Fiscal decentralization and growing regional disparities in rural china: Some evidence in the provision of social services," Oxford Rev. Econ. Pol., vol. 11, no. 4, 70-84, 1995.
[5] R. Ashley, C. W. J. Granger, and R. Schmalensee, "Advertising and aggregate consumption: An analysis of causality," Econometrica, vol. 48 , no. $5,1149-1167,1980$.

[6] R. F. Engle, and C. W. J. Granger, "Cointegration and error correction: Representation, estimation and testing," Econometrica, vol. 55, no. 2, 251-276, 1987.

[7] C. W. J. Granger, and P. Newbold, "Spurious regressions in econometrics," Journal of Economics, vol. 2, no. 2, 111-120, 1974.

[8] H. Toda, and P. C. B. Phillips, "Vector autoregressions and causality," Econometrica, vol. 61, no. 6, 1367-1394, 1993.

[9] H. Y. Toda, "Finite sample properties of likelihood ratio tests for cointegrating ranks when linear trends are present," The Review of Economics \& Statistics, vol. 76, no. 1, 66-79, 1994.

[10] H. Y. Toda, and T. Yamamoto, "Statistical inference in vector autoregressions with possibly integrated processes," J. Econometrics, vol. 66, no. 1/2, 225-250, 1995.

[11] D. A. Dickey, and W. A. Fuller, "Distribution of the estimators for autoregressive time series with a unit root," J. Amer. Stat. Assoc., vol. 74, no. 386, 427-431, 1979.

[12] W. A. Fuller, Introduction to statistical time series, New York: John Wiley, 1976.

[13] P. C. B. Phillips, and P. Perron, "Testing for a unit root in time series regression," Biometrika, vol. 75, no. 2, 335-346, 1988.

[14] W. K. Newey, and K. D. West, "A simple, positive semi-definite, heteroskedasticity and autocorrelation consistent covariance matrix," Econometrica, vol. 55, no. 3, 703-708, 1987.

[15] S. Ng, and P. Perron, "Unit root tests in arma models with data dependent methods for the selection of the truncation lag," J. Amer. Stat. Assoc., vol. 90, no. 429, 268-281, 1995. 